\title{
NATURE-DEFICIT DISORDER IN MODERN CITIES
}

\author{
ANOUSHEH S. M. NIKKHOU \& AZIME TEZER \\ Urban and Regional Planning Department, Istanbul Technical University, Turkey
}

\begin{abstract}
Over the last century, urbanization has become one of the most important topics that has effects on several aspects of citizens' health. According to the World Bank report, $68 \%$ of the world's population will live in cities by 2050 . This change in lifestyle of humanity has several effects on urban health, which include urban governance; population characteristics; the natural and built environment; social and economic development; service and health emergency management; and food security. The characteristics of urban open spaces have specific impacts on citizens' health. The population growth in developing countries, especially in Asian countries, has caused a decreasing rate of open spaces per person in recent years and it could be worse in the future. The impact of natural areas on children's health and how it would be effective on Nature-Deficit Disorder treatments, which cause several mental and physical issues for children, is the focus of this study. The main idea of this study is based on the Nature-Deficit Disorder concept, which has discussed by Richard Louv regarding the importance of nature connection on children's wellbeing. In this study, an in-depth interview was conducted with primary school students - children between age 4 and 12 - and their teachers in Mazandaran, the northern and green province of Iran, and the educational environment has been selected as a tool to measure the impacts of being in nature as a daily activity of children's wellbeing and their learning quality. As a result of the research, we found that students with more daily nature connection at school or in their neighborhoods have better performance and capability at school and also in their social and cognitive skills.

Keywords: children as citizens, urban health, nature-deficit disorder (NDD), children's health, education facility, urban planning.
\end{abstract}

\section{INTRODUCTION}

Urbanization is a fundamental change in the history of human life. For several centuries, urban areas have been the main settlement for humans. Base on the UN report in 2018, 55\% of the world population are living in urban areas and it has predicted that this will grow to $68 \%$ by 2050 , and as a result of urbanization, the overall world population growth will be affected and 2.5 billion people will be added to the population of urban areas. Additionally, $90 \%$ of this population growth will take place in Asia and Africa [1]. Humans used to live in rural and natural environments for thousands of years and after the impact of the industrial revolution, the huge shift of population to urbanized areas brought diverse challenges on earth. The physical activities had decreased rapidly, people started to live inside the built spaces with artificial materials and caused less and less nature contact in their daily life. It is proved that the nature connection has direct and unneglectable positive impacts on cognitive and social growth [2]. Regarding these facts, the sustainable interaction between built components of cities and the natural environment is critical for people to keep themselves in balance; physically and mentally. According to the newest UN's world population report, around $25 \%$ of the world population are under the age of 14 [3]. Due to the noticeable percentage of the young population in cities, this group is one of the main users of the urban environment who are in their critical ages to shape their physical and mental wellness. Urban lifestyle, working parents, educational systems are the reasons that increase the time that children spend their time out of the houses, in childcare centers or schools. Environmental factors, on the other hand, have direct and indirect impacts on children's growth process too. 
Nature-Deficit Disorder (NDD) is a concept in the literature that includes a list of physical and mental disorders that are the consequences of a sedentary lifestyle and of being inside buildings and mainly built-up urban environments and the symptoms are more diagnosed in children under age 12. If they do not treat them well through their growing periods, their problems will shape their adulthood and will have various negative impacts on their social behavior, physical and mental wellness [2]. According to these arguments, having healthy cities will provide healthy and socially active citizens. Therefore, this research focuses on the NDD concept and the importance of public access to natural areas for daily, weekly, monthly, and yearly activities in urban life "as a diet".

In the literature, having daily nature connection and playing freely in open areas, inside neighborhoods in childhood periods, empower kids' social networks which will make them more responsible and socially attached adults [4]. Therefore, in this study, primary school children were chosen as a school children level to understand the characteristics of urban level NDD if exists in the case of Iran, Mazandaran region. Urbanized children under age 12 spend their major active hours inside primary schools. So, the physical characteristics of primary schools and the surrounded environment are critical spaces for them to spend some time on their physical and mental wellness. Therefore, in this study, the characteristics of primary schools with their outdoor facilities and their connectivity potentials to nature/semi-nature spaces will be searched in the case of Iran. The research has done in the north region of Iran, where green natural spaces are more available than other parts. The center of the study is Chamestan - a small city located in the south of Caspian Hyrcanian mixed forests. 25 primary students and 16 teachers have been chosen for an interview about their observation, experiences, and aspect of the educational environment and green spaces in their neighborhoods. The basic results show that the environment of schools, where both groups spend the majority of their daytime, has clear positive impacts on the quality of education and well-being.

The main question of this research is, "How to protect urbanized children from NDD?" To answer this question, at first, the definition of NDD and its consequences are necessary. After clarifying the definitions and position of children in urban areas, finding a practical option that is familiar for children is the next step. Here, primary schools as an educational facility that has a huge role in children's growth and well-being have been chosen. As the next step, Mazandaran province in the north of Iran has been selected depending on the geographical features. Then, some in-depth interviews with primary students, teachers, and educational activists have been done to collect information on the current situation of the selected cases. In these interviews their needs, suggestions to improve the condition, and experiences have discussed to determine the practical impacts of nature connection on children's wellness (see Fig. 1).

Unfortunately, after the impact of the COVID 19 pandemic, the field studies of this research have not been completed, so this paper has written based on previous studies and limited data collected before the pandemic.

\section{CHILDREN AS CITIZENS}

Generally, a quarter of the world population is children being under age 14 [3]. This significant number has lots of means to planners and urban stakeholders. One of the main user groups of cities is children, but in most of the modern urban areas, there are some limited spaces specially designed for them. From the first moments of life, children are super recipients, they start to be active, social, and curious about knowledge, space, and culture. They are active settlers and create their self-identities by engaging society and cities, so they have to participate in urban planning and have their special facilities and areas to grow in a 
healthy environment [5]. Concerning the hectic lifestyle of urban environments, citizens spend the majority of their days inside different buildings and built environments. For kids, it is essential to have some active hours in open spaces to improve their mental and physical skills [2]. The concept of Nature-Deficit Disorder (NDD) has been raised by Richard Louv in his prominent book the Last Child in the Woods. In this book, he discusses several symptoms that are the consequences of the lack of nature connection which include; obesity, hyperactivity, attention problems, and vascular disorder issues. In the urban environment, educational places are the first official contact areas that kids start socialization and participating in social life. The physical characteristics of these areas, therefore, have long-term deep impacts on children's health and well-being. Respect to the NDD concept and its impacts on society, this study is about the combination of land use/spatial planning and health factors that are influential on children's growth.

Children are not only the current users of cities, but they are also the future decision-makers for cities. Due to this fact, educators and spatial planners have the responsibility to consider their well-being, and urban planning might have its role to create more sustainable and healthy cities for the future [5]. The role of educators in teaching children for their connection and their behavior to their environment is not the purpose of this paper but instead, this paper's focus is to clarify the role of urban planners to consider children as citizens but not treating them as invisible city users.

In this study educational places have been studied as a tool to improve kid's nature connection and diet for their well-being and protection from NDD. Therefore, in land-use planning, decision-makers and stakeholders have to consider the spatial characteristics of educational facilities and their environments to reach the most efficient functions for the well-being of users. Thus, moreover, the building form and yard situation, neighborhood characteristics, and accessibility to open space/green areas around schools will be important and also necessary.

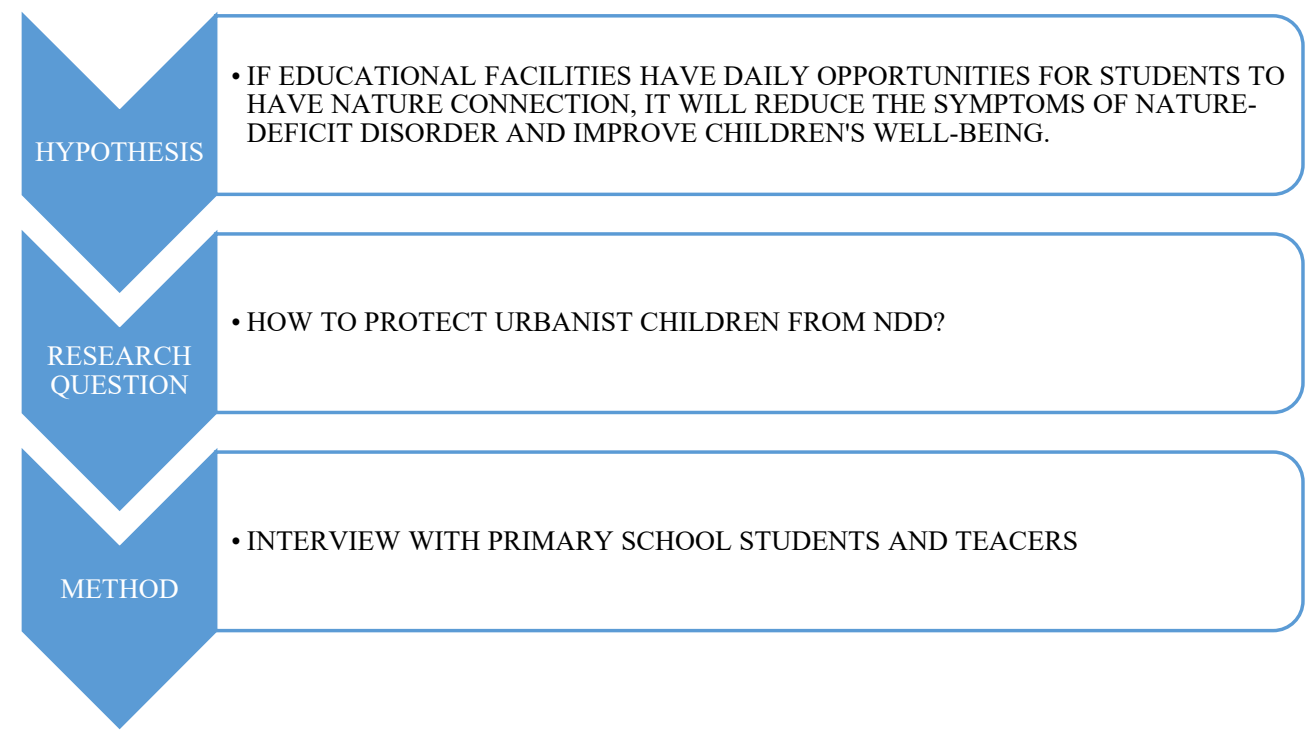

Figure 1: The research process. 


\subsection{The concept of urban health and well-being}

A rapid rise of urbanization and the intricacy of urban structures and the complexity of diverse factors have made the urban health one of the hottest topics all around the world. At first, it is necessary to take a quick look at the definition of urban health and well-being. Urban health includes a group of social and physical features that are the results of urban infrastructures that have impacts on public health and quality of life in urban areas. Well-being is a concept with three main elements; happiness, life satisfaction, and quality of life. The combination of urban health and well-being shapes the concept of urban wealth, which means the overall level of quality of life and satisfaction of a city [6]. The quality of urban wealth is determined by several factors such as individual physical, mental, emotional aspects of health [7]. An unhealthy urban environment has negative impacts on citizens, such as; physical health problems, mental illnesses, reduction of productivity, increasing the general stress level. Urban green/open spaces, on the other hand, have therapeutic impacts for citizens, they improve mental and physical health and also reduce urban environmental quality problems like air and noise pollutions in cities [8]. Since the $19^{\text {th }}$ century, during industrialization and the rapid growth of urbanization, urban health becomes one of the growing concerns in urban studies [9]. Urban health is measured by several indicators such as; physical, biological, chemical, and social factors, but in spatial planning, the main factor to measure the level of quality of life in the urban environment is related to the accessibility to green areas [10].

\subsection{Children's ecological behaviour}

In this study, educational facility areas have studied as their potential to be an instrument to improve children's nature-diet and protect them from NDD. The physical characteristics of educational facilities have direct impacts on well-being. Playing in open/green spaces empowers children's nature knowledge and they will try to find their solutions in different situations, which will increase their creativity and social skills [4]. A study has been completed at the University of California shown children with environmental knowledge and spends time outdoor to play, more than $50 \%$ of them were conscious about environmental values and feel a responsibility about environmental issues, and also they had biodiversity knowledge and ecological behavior [11]. There are not any scientific pieces of evidence to prove that parents' environmental attitude will have significant effects on children's ecological behavior [12] but the indirect learning, being in natural places and observing teachers and other children's behaviors have significant impacts on children learning process and improving their ecological attitudes [13]. For instance, in 2013, Collado et al. have done a study to assert children's ecological behaviors, they divided their foundlings into general groups; which are; daily conservation actions and environmental citizenships behaviors [14]. Regarding Collado's results, characteristic of educational environments and access to green spaces have significant impacts on children's ecological behaviors, social growth, and responsibility [15]. Another project that has done in this topic is the project was performed in 2019 by Istanbul University to improve students' nature connections and then measure the results in 7-8-year-old students [16]. They collected 90 students from primary schools of 3 districts of Istanbul - Uskudar, Umraniye, and Kagithane. They did 100 activities in forest areas of Istanbul in 3 modules that were; Natural activities, city-based activities, and social activities to improve the students' nature and social knowledge. These programs had been held at weekends for one year. In their Nature Module, they did three walking programs in three different regions; Belgerad forests, around the path of Bosporus Chanel of Istanbul, and 
Sile District. These walking journeys have taught students to understand the cooperation between nature and the city, also their families have reported that they consider significant differences in their children, they became calmer and also more responsible about their neighborhood and environment, additionally, children were excited to teach their achievements to their siblings and friends [17]. Studies like the Istanbul University's project have shown the importance of nature connection and nature-based education programs on children's growth path and their health.

\section{IMPORTANCE OF EDUCATIONAL LAND-USE IN CITIES}

Dramatically change in lifestyle in the last two decades has a high range of consequences on public well-being and health, people have very limited time to spend for family recreational activities outdoor in natural areas [18]. In spatial planning, any type of land-uses has its characteristics and social impacts, all built areas, regardless of the function, need to have access to green/open spaces to support the wellness of the consumers [19]. Therefore, educational facilities have to have suitable access to green/open spaces to improve students'/children's wellness and provide opportunities for them to explore the environment and learn how to deal with it. They learn and gain critically important skills in these places through their cognitive growth which is directly affected by the conditional and contextual features of educational methods and facilities itself. Hence, the qualifications of educational facilities/spaces have to provide opportunities for physical and mental well-being through built and natural elements and connections. Children need to be free to play in open spaces and discover their environment. An aspect of urban planning, it's planners' rule to pick open and near to green places as educational lands and consider conservational policies for the surrounding area to keep it green and open.

\subsection{Physical features of educational facilities}

The physical features are not just about the buildings, also the whole process from home to school area matters. Having sustainable and accessible transportation for all users, like bike roads or safe and pedestrian-friendly streets to walk to school, and enjoy and experience the way to schools [5] will provide healthier experience to learn and enjoy. The essential step to improve urban physical conditions and the public level of health is, participating in the community to make decisions [8]. The main users of the primary and secondary school areas are students who are under age 14, so to rethink the functions and improve the environmental effects of school buildings is necessary to observe students' thoughts and ask them about their needs and desires related to their schools and the environment from home to school areas.

As a result, one of the important factors to improve activities in natural and open spaces is empowering the quality of the environment by providing safe and secure places for children to play and to have experience freely. To protect children from NDD they need to have access easily to green open spaces near their schools and their homes, which is more possible in peripheral areas of large cities [2]. Reducing the nature connection in educational activities is not just about public education and formal curriculums, it could also be managed by educational activities that are planned by other scientific institutions. Regarding Iranian official regulations for designing primary school define 3 main standards for schoolyard; (1) the yard surface has to be flat an accessible for disabled people's movement, (2) there should be at least 20-25 $\mathrm{m}^{2}$ per person green spaces, (3) Asphalt and coarse-grained concrete are recommended materials for surfacing schoolyard [20]. The above regulations refer to the schoolyard and inside features, here it is necessary to take a look at primary school location, 
the Iranian regulations are based on 3 main categories for selecting primary school locations which are adjoining, location, and capacity [20]. Adjoining refers to surrounding places that have to be protected from various types of pollutions - air, noise, and environment. The location principles regard to accessibility and neighborhood characteristics, school ways have to be suitable and secured for students to walk or bike to school. The capacity refers to the size of land which has to be consonant with the number of students and educational activities [20]. Regardless of Iranian regulations, the Radburn concept is also related sample to make clear importance of neighborhood network and physical features of lands [20]

\section{CASE STUDY}

In this study, the focus is on the location of educational facilities and accessibility to urban open green spaces, so the peripheral part of Nour county has chosen. The city "Chamestan" is located in Nour county in north Alborz foothills which have suitable accessibility to natural areas and most of the city is green (see Figs 2 and 3).

\subsection{Physical characteristic}

The Caspian Hyrcanian mixed forests with more than $55000 \mathrm{~km}^{2}$ area [21]. Approximately $1 / 3$ of the city is covered by the Hyrcanian forest, and this feature provided suitable access to natural green areas. The pristine and pure nature of the forest made the area one of the most important natural heritages of the region.

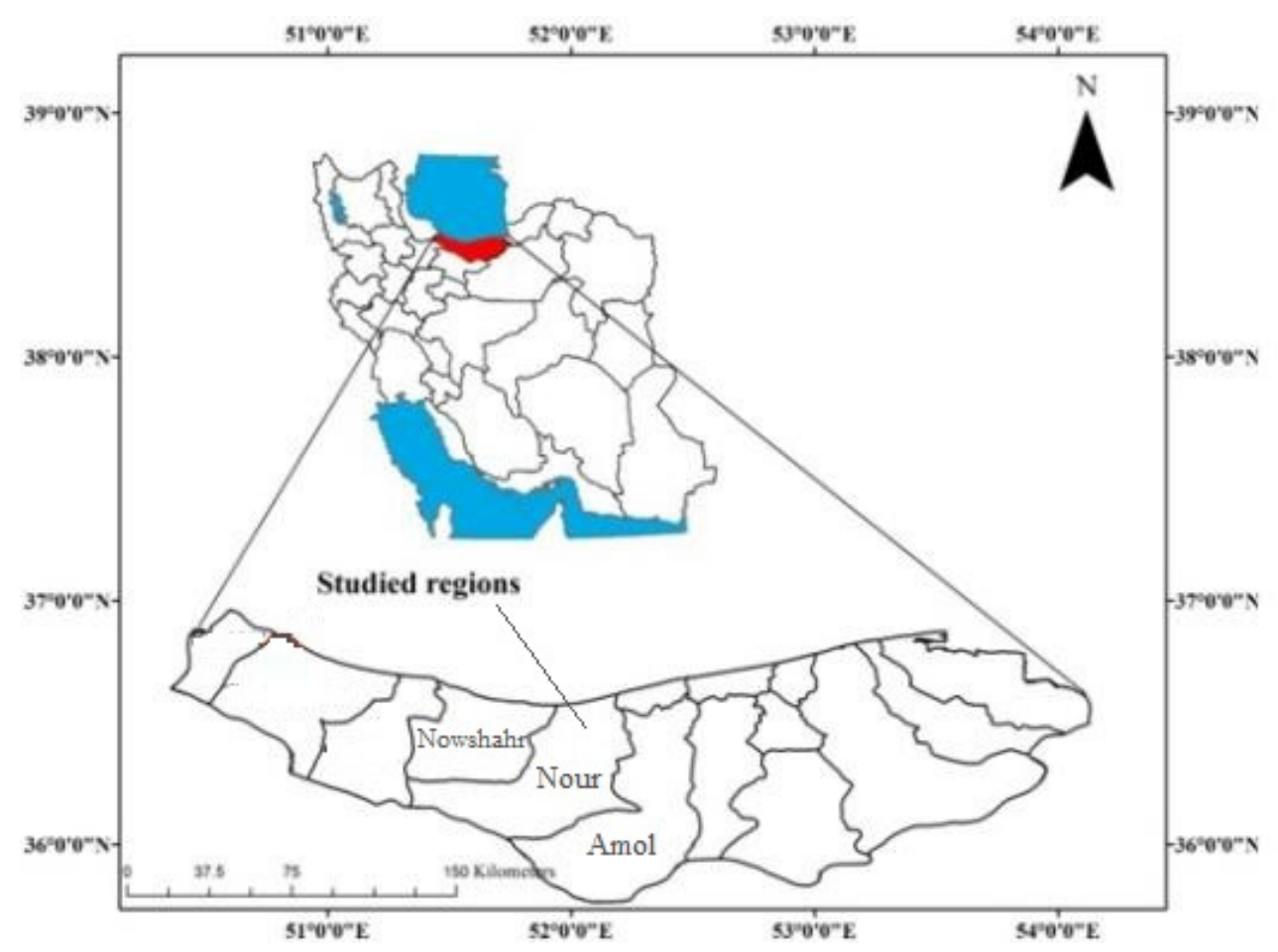

Figure 2: Location of Mazandaran province in Iran [17]. 


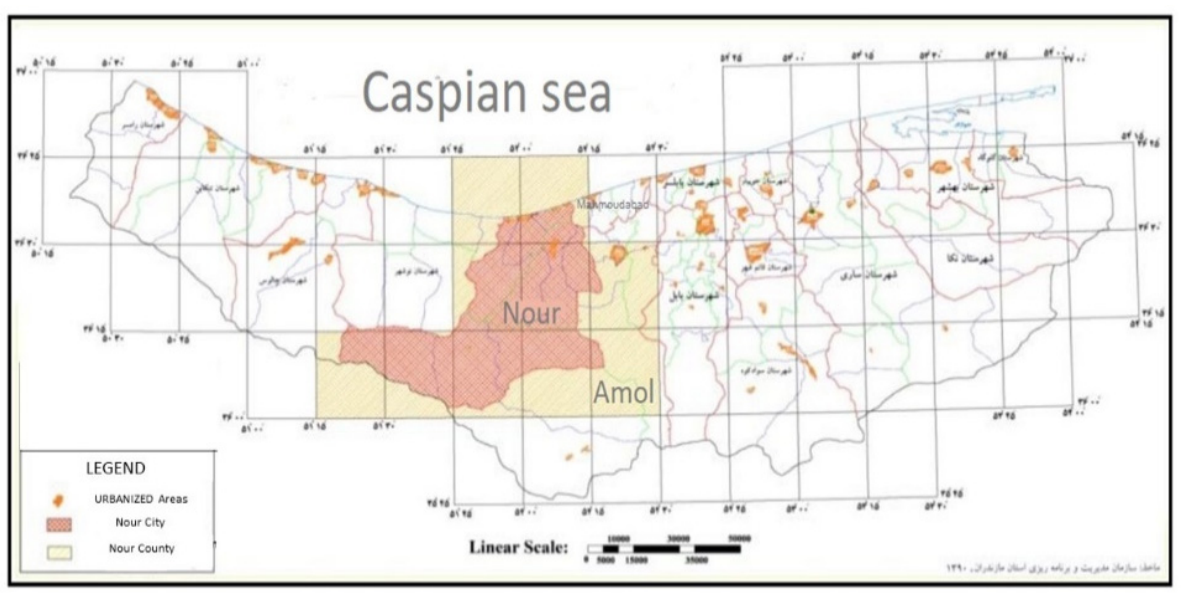

Figure 3: Nour county location and neighbors [17].

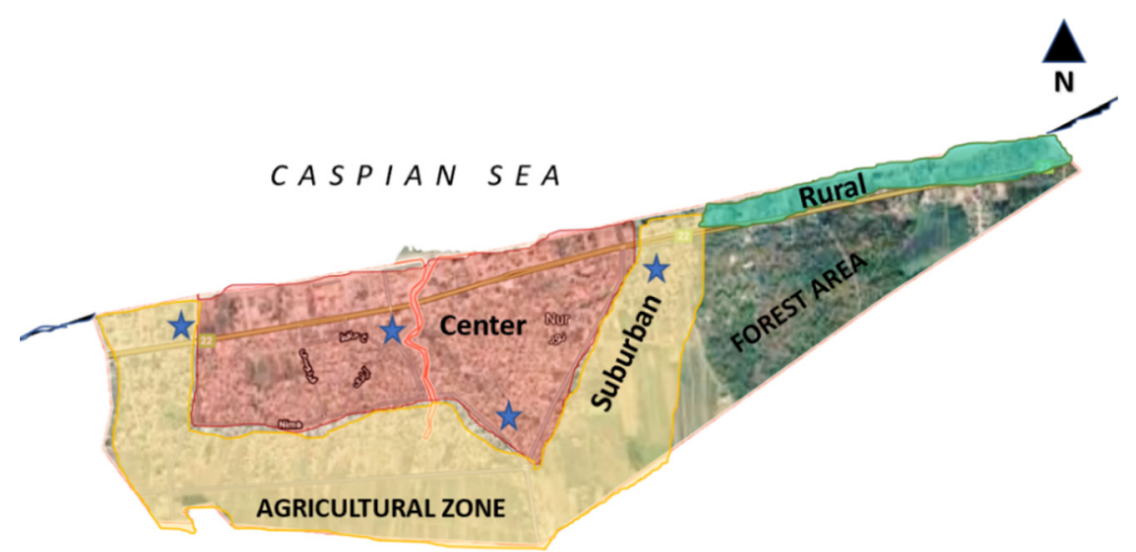

$\downarrow$ PRIMARY SCHOOL

Figure 4: Nour city physical characteristic.

\subsection{Data collection}

The in-depth interview has been done in 3 main zones; rural area, sub-urban area, and urban area (see Fig. 4). The surveys have filled by 25 primary students, 6-12-year-old, who are studying in public schools. And also, by 16 teachers in primary schools. The interviews have been done in 3 sections; observations, current situation, and future plans. Due to the importance of participating children in the decision-making process, children's expectations about their needs and ideas related to their schools' environment and also their neighborhood were asked. In the rural part, children have better access to natural places. Though the 
building of the schools is not well developed and the schoolyard is not designed properly according to their needs and they are just an open space as entrance and morning speeches but students have more opportunities to play freely in this open space and also after schools, they have green areas near schools and their homes. Children expect more natural elements in their schoolyard, in the current situation all the schools that have been visited for this research were asphalt surfaced and just 2 or 3 plants or trees are existing in the yard and the surrounding environment of schools are just built element. In the rural part, the condition is better than the urban area, based on the geographical feature of the location (see Fig. 5).

\section{RESULTS}

In this research, students have asked about the daily time that they spend outside and the possibilities that they have in their schoolyard and also in their neighborhood. Students have been also asked about open green spaces in their neighborhood, but most of them were in the same position as their schoolyard; they are not allowed to play in grass and playground are surfaced by artificial materials. Children wish to have green and free spaces to play and use natural elements such as wood and stone.

In public schools, unfortunately, neither in curriculums nor the physical facilities, outside times and environmental studies have not considered, but there are few private primary schools - which are not affordable for all the citizens, with environmental programs named Nature Schools. in nature schools, all the physical principles and educational curriculums are based on nature connection and its benefits. A teacher who is working in one of these nature schools said about her experience; "I have an 8-year-old student, who used 7 pills per day to control his hyperactivity, attention disorder symptoms and behavior disorder but after being in nature school for just 5 months his doctor stopped the medications". There are several same experiences in the interviews result that teachers found considerable positive changes in students behavior and learning after having a nature connection. This opportunity has to provide for all primary schools to improve students' well-being and empower their social skills. Another result that is considered about the positive impacts of nature, is that students said that after playing in the yard they can learn mathematics and science better. This result and previous studies on the impacts of nature on learning capacity [4], proves that if children spend their break time in a garden as a schoolyard, it will have significant improvement in their lessons.

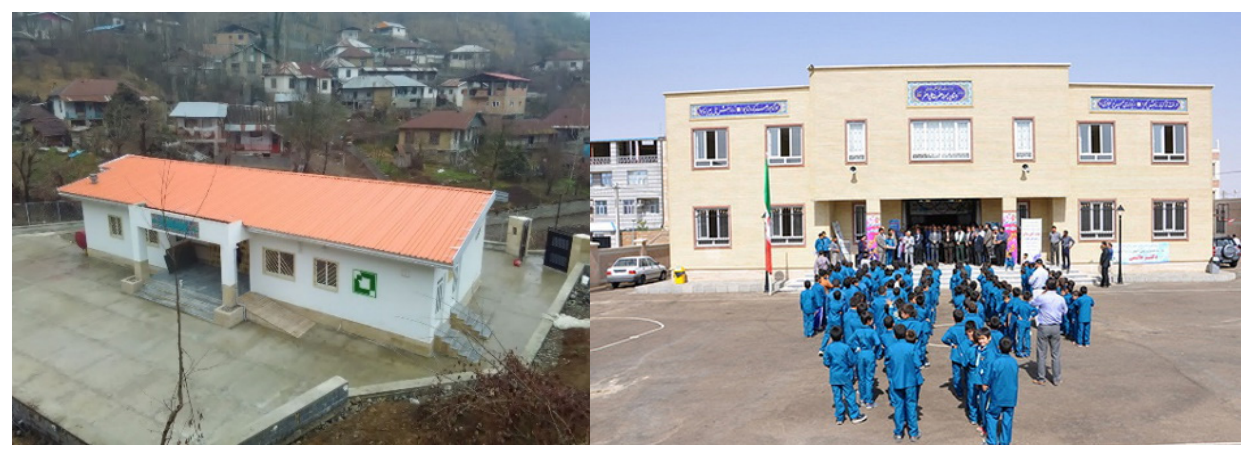

(a)

(b)

Figure 5: A primary school. (a) A rural part [22]; and (b) An urban part [23]. 


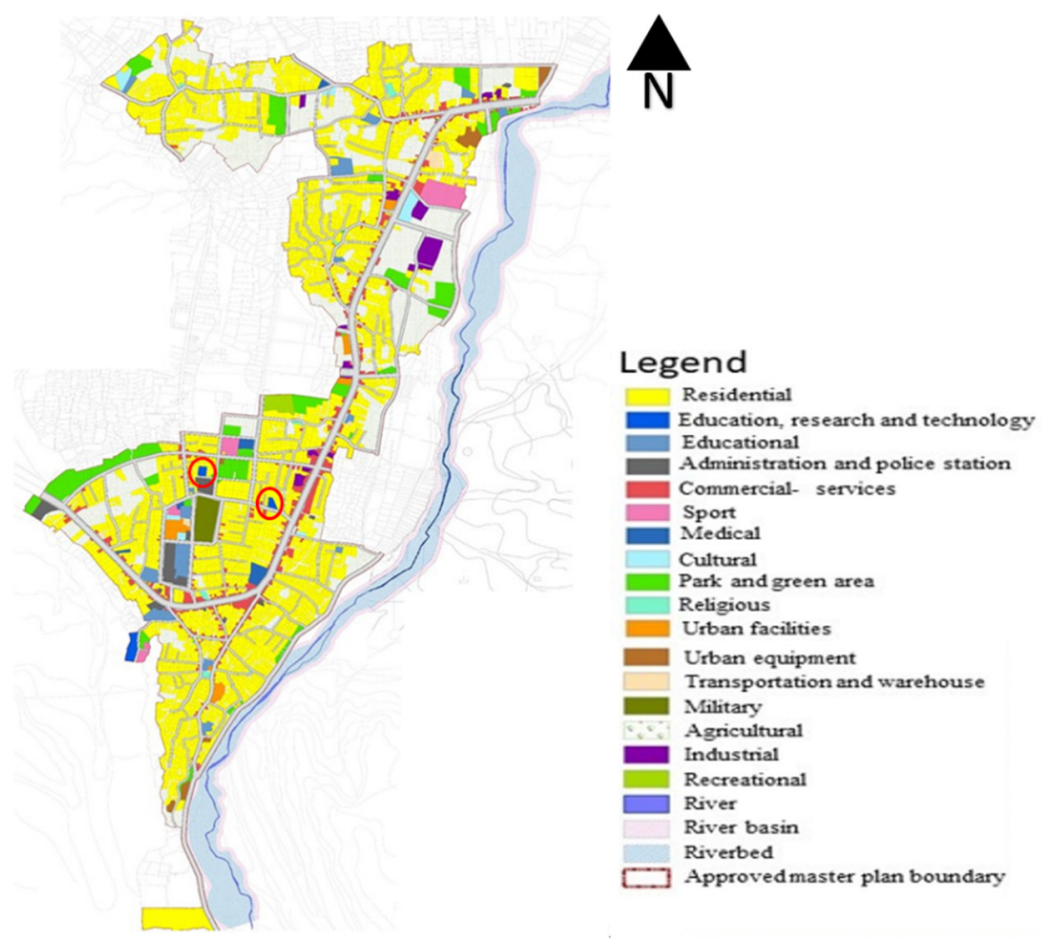

Figure 6: Chamestan (sub-urban area) current land-use map [17].

In Fig. 6, the land use of the selected sub-urban area has been studied shown. The red circles show the location of primary schools, regardless of the location of this small city that is very close to natural places, the primary schools are located at a significant distance from forest areas. This is a serious negative point that keeps students far from the natural environment. And also, students even in the sub-urban area wished for more nature in schoolyards. As mentioned above in Iranian regulation, the recommended material for the schoolyard is asphalt and concrete which are not natural at all. Results show the regulations need to restructure and consider natural elements more in new regulations. Urban planners and decision-makers have to choose bigger and greener locations for educational land-uses.

\section{CONCLUSION}

This study focuses on the literature studies about the importance of natural elements and urban open spaces on children's health and well-being as they are the quarter of urban population together with a survey handled Nour City of Iran's primary school children and teacher's opinions. Educational facilities as a tool have been considered to study primary students' and teachers' experiences about being in nature in school hours. The interviews which have done with primary students and teachers in Nour province - located in Mazandaran, north of Iran, have shown that students who are studying in public primary schools, can feel the lack of natural elements in their schoolyards and they asked for more greenery inside their schoolyards. Both teachers and students have pointed the same experiences that after being in nature and playing there the, learning quality and students' 
attention to the lessons were tangible enough to improve their interaction. Children as citizens have to be part of spatial planning and planners have to consider their needs to have healthier generations and more sustainable cities. The literature studies show children who spend more time in nature are more responsible citizens in their adulthood for their environment. Regarding the results and designing regulations, choosing primary school's location and also the accessibility to natural parts of the city is critical in urban planning and also in educational programs.

\section{ACKNOWLEDGMENTS}

Special thanks to the Management and Planning Organization of Mazandaran province to give me spatial data generously and the Child and Nature Institute of Iran. And all of the schools' staff and students in Nour, Chamestan, and Joorband who helped me to complete my field studies. Without their support and their assessments, this research would not be completed.

\section{REFERENCES}

[1] UN, $68 \%$ of the world population projected to live in urban areas by 2050 , says UN. United Nation-Department of Economic and Social Affairs, New York, 2018.

[2] Louv, R., Last Child in the Wood, Workman Publishing Company, 2005.

[3] UN, World Population Prospects 2019. United Nations, Department of Economic and Social Affairs, 2019.

[4] Pyle, R.M., The Thunder Tree: Lessons from an Urban Wildland, Oregon State University Press, 1993.

[5] Holden, C. \& Clough, N., Children as Citizens: Education for Participation, J. Kingsley, 1998.

[6] Galea, S. \& Vlahov, D., Handbook of Urban Health, Springer: Boston, 2005.

[7] Krefis, A.C., Augustin, M., Schlünzen, K.H., Oßenbrügge, J. \& Augustin, J., How does the urban environment affect health and well-being? A systematic review. Urban Science, 2(1), pp. 21, 2018.

[8] WHO, Urban green spaces and health - A review of evidences. WHO, regional office of Europe, 2016.

[9] Cummins, S., Curtis, S., Diez-Roux, A.V. \& Macintyre, S., Understanding and representing "place" in health research: A relational approach. Social Science and Medicine, 65(9), pp. 1825-1838, 2007.

[10] Kruize, H., On environmental equity: Exploring the distribution of environmental quality among socio-economic categories in The Netherlands, Koninklijk Nederlands Aardrijkskundig Genootschap: Utrecht, 2007.

[11] Kaiser, F.G., Ranney, M. \& Harting, T.A.P., Ecological behavior, environmental attitude, and feelings of responsibility for the environment. European Psychologist, 4(2), pp. 59-74, 1999.

[12] Evans, G.W., Brauchle, G., Haq, A., Stecker, R., Wong, K. \& Shapiro, E., Young children's environmental attitudes and behaviors. Environment and Behavior, 39(5), pp. 635-659, 2007.

[13] Stern, P., Toward a coherent theory of environmentally significant behavior. Journal of Social Issues, 56(3), pp. 407-424, 2000.

[14] Collado, S., Staats, H. \& Corraliza, C.J., Experiencing nature in children's summer camps: affective, cognitive and behavioral consequences. Journal of Environmental Psycology, 33 pp. 37-44, 2013. 
[15] Collado, S., Corraliza, J.A., Miguel, S.A. \& Evans, G.W., Spanish version of children's ecological behavior (CEB) scale. Piscothema, 27(1), pp. 82-87, 2015.

[16] Istanbul University, Adaptation of Istanbul Children to Nature and the City Project, Istanbul University Press: Istanbul, 2019.

[17] M.a.P.O.o.M. Province, Master plan, Municupality of Mazandaran, Sari, 2011.

[18] North Carolina State University, Benefits of connecting children with nature: Why naturalize outdoor learning environments. Natural Learning Initiative, 2012.

[19] Flacke, J. \& Kockler, H., Saptial urban health equity indicators-a framework-based aapproach supporting spatial decision making, WIT Transactio on Ecology and The Environment, vol. 193, 2015.

[20] Ahmad Mahmoudi, A., Memari Nou, New architecture, 2011. http://98str.blogfa.com/post/32.

[21] Martin, M., Returning to Radburn. Landscape Journal, 20, pp. 19, 2001.

[22] D.a.E.o.M.S. General Office of Renovation, Development and Equipping of Mazandaran Schools, 2017. www.nosazimaz.ir/photo/gridall/Photo_page/21/Photo_ sort/Photo_Tag.

[23] Mahjuri, A., qomnews, 2017. http://tnews.ir/site/c9b4105176023.html. 